\title{
KETAMINAS POOPERACINIAM SKAUSMUI GYDYTI
}

\author{
Greta Kasputyte் $\dot{1}^{1}$, Aurika Karbonskienè ${ }^{2}$ \\ ${ }^{1}$ Lietuvos sveikatos moksly universiteto Medicinos akademijos Medicinos fakultetas, \\ ${ }^{2}$ Lietuvos sveikatos moksly universitetoMedicinos akademijos \\ Medicinos fakulteto Anesteziologijos klinika
}

Raktažodžiai: ketaminas, ūmus skausmas, pooperacinis skausmas, pooperacinè analgezija.

\begin{abstract}
Santrauka
Efektyvus skausmo gydymas po operacijų sudaro sąlygas pilnavertei ankstyvajai reabilitacijai ir gali prisidèti gerinant chirurginio gydymo rezultatus. Nuolat ieškoma naujų pooperacinès analgezijos vaistų ir jų derinių, užtikrinsiančių optimalų skausmo gydymą su kuo mažesniu nepageidaujamų reiškinių dažnumu. Ketaminas - seniai naudojamas bendrasis anestetikas. Jis mažomis dozėmis gali būti panaudotas kaip vaistas-priedas pooperacinei analgezijai. Straipsnyje apžvelgiami tyrimai, kurių rezultatai leidžia teigti, kad mažos ketamino dozès yra saugios ir gali sumažinti stiprių, opioidinių analgetikų poreikị po operacijos.
\end{abstract}

\section{Ivadas}

Pooperacinis skausmas - aktuali šių dienų medicinos problema. Nepaisant vis didejjančios mokslo pažangos ir irodymais pagrịstos medicinos taikymo praktikoje, daugiau nei 80 proc. pacientų po įvairaus pobūdžio operacijų patiria stiprų ūmų skausmą. Net 75 proc. iš jų skausmą apibūdina kaip vidutinio sunkumo, sunkų ar nepakeliamą $[1,2]$. Šios studijos patvirtina, kad šis pooperacinis skausmas vis dar yra gydomas netinkamai. Jis yra susijęs su ilgesniu atsigavimu po operacijos, didesniu pooperacinių komplikacijų dažnumu, mažesniu pacientų pasitenkinimu, blogesne gyvenimo kokybe [3]. Siekiant geresnių baigčių po operacijos, 2016 metais Amerikos skausmo draugija paskelbè naujas pooperacinio skausmo valdymo gaires. Jose didelis demesys skiriamas daugialypiam (angl. multimodal) skausmo gydymui, siekiant suderinti medikamentinio bei nemedikamentinio gydymo būdus, veikiant tiek periferinę, tiek centrinę nervų sistemas [4]. Daugialypę analgeziją sudaro periferinių ir centrinių nervų blokados, vietinè infiltracija bei sisteminis vaistų poveikis. Vienas iš jos variantų yra opioidinių analgetikų deriniai su vaistais-priedais: gabapentinoidais, metadonu, $\alpha_{2}$ adrenore- ceptorių agonistais, magniu, lidokainu, deksametazonu ar ketaminu [5]. Vaistų-priedų vaidmuo skirtingose chirurgijos srityse ir įvairioms pacientų grupèms dar nèra gerai ištirtas. Jų vietą gydant skausmą dar teks surasti [6-10].

Darbo tikslas: apžvelgti ketamino tyrimų istoriją ir dabartinị vaidmenị gydant pooperacinị skausmą.

\section{Darbo objektas ir metodas}

Ruošiant šį straipsnị buvo apžvelgtos mokslinių publikacijų duomenų bazès PubMed, Sciencedirect, atlikta straipsnių ir rekomendacijų apžvalga. Paieškai taikyti buvo panaudotos šių raktinių žodžių kombinacijos: ketamine/acute pain/postoperative pain/analgesia/perioperative analgesia. Prioritetas buvo teikiamas šaltiniams, publikuotiems anglų kalba. Nagrinèti straipsniai, kuriuose pateikiami ketamino dozavimo protokolai, pooperacinio skausmo intensyvumas bei kitų analgetikų poreikis po operacijos. Rezultatai pateikiami straipsnyje.

Ketamino tyrimų istorija. Siekiant sukurti ir ị anesteziologijos klinikinę praktiką ịdiegti naują medikamentą, analgetinėmis ir anestezinėmis savybėmis panašų i fenilciklidinus (PCP), tačiau trumpesne veikimo trukme ir silpnesniu psichomimeziniu poveikiu, 1962 metais Calvin Lee Stevens susintetino medžiagą CI-581, šiuo metu žinomą ketamino pavadinimu.

Po 2 metus trukusių ikiklinikinių studijų, 1964 metais rugpjūčio $3 \mathrm{~d}$. ketaminas pirmą kartą buvo panaudotas žmonių anestezijai sukelti. Vaisto dozè svyravo $0,1 \mathrm{mg} / \mathrm{kg}-2$ $\mathrm{mg} / \mathrm{kg}$ ị veną (i/v). Nustatyta, kad pusè tiriamujų netekdavo sąmonès suleidus $i \mathrm{i} / \mathrm{v} 0,5 \mathrm{mg} / \mathrm{kg}$ ketamino, o suleidus $i \mathrm{v} 2$ $\mathrm{mg} / \mathrm{kg}$ sukelta koma truko vidutiniškai $10 \mathrm{~min}$. Nepageidaujamas vaisto poveikis pasireiške maždaug 1 iš 3 tiriamuju, o pooperacinis delyras buvo minimalus [11-12].

Tolesniuose 1965 m. Guenter Corssen ir Edward F. Domino atliktuose tyrimuose nustatyta, kad CI-581 slopina centrinès nervų sistemos gebejjimą reaguoti į tam tikro stiprumo sensorinius impulsus, tačiau nesukelia pilnavertės jų blokados. Todèl ketamino sukeltai būsenai apibūdinti buvo 
pasiūlytas naujas terminas - disociatyvi anestezija. Buvo pastebèta, kad nepageidaujamas psichomimezinis ketamino poveikis pasireiškè būtent tada, kai pacientai budimo iš anestezijos metu veikiami išoriniais taktiliniais ar verbaliniais dirgikliais [13]. Vèliau, 1968 m. 42-ame ,International Anesthesia Research Society" kongrese tie patys autoriai patvirtino, kad ketaminas slopina asociacinę žievę ir tokias požievines struktūras kaip gumburas, tačiau tuo pačiu metu stimuliuoja limbinès sistemos dalis, pvz. hipokampą. Taip pat nustatyta, kad ketaminas adekvačiai blokuoja somatinio skausmo impulsų plitimą, tačiau jo poveikis yra nepakankamas visceraliniam skausmui slopinti. Tai išryškejjo urologinių manipuliacijų metu pacientams, kuriems dèl padidèjusio šlapimo pūslès sfinkterio tonuso ir šlaplès striktūrų, taikant anesteziją ketaminu, išliko papildomų intraveninių analgetikų poreikis. Tame pačiame kongrese buvo pristatytos pirmosios klinikinès ketamino vartojimo rekomendacijos. Atsižvelgiant ị tai, kad vaikams ir kūdikiams, lyginant su suaugusiais, nepageidaujamas psichomimezinis vaisto poveikis pasireiškè itin retai, ketaminą buvo siūloma naudoti pediatrinių chirurginių intervencijų metu, išskyrus tam tikrus atvejus, kai dèl savo specifinių savybių naujasis vaistas buvo pranašesnis už kitus standartinius anestetikus [14].

$1982 \mathrm{~m}$. Royal veterinarijos universitete Londone atlikta studija su katemis pirmą kartą parodè, kad ketaminas, veikdamas kaip $N$-metil-D-aspartato (NMDA) receptorių antagonistas, selektyviai slopina posinapsinių impulsų plitimą. Šis naujas atradimas lëmè dar didesnị mokslininkų susidomėjimą vaistu - atskleistos jo analgetinès savybès [15].

Ketamino veikimo mechanizmas. Žinoma, kad ketaminas veikia ne tik kaip NMDA receptorių blokatorius, kuris prisijungia prie PCP jungimosi vietos, esančios NMDA receptorių komplekse ir sumažina membranos depoliarizaciją, tačiau veikia ir kitose sinapsinio tarpo vietose [16]. Tyrimai in vitro ir eksperimentiniai tyrimai su gyvūnais parode esantị sinergistinị ryšị, vartojant ketamino bei opioidų kombinaciją [17]. Todèl ketaminas, veikdamas kaip kappa ir miu opioidinių receptorių agonistas, gali būti naudojamas kaip adjuvantas ịvairios etiologijos skausmui malšinti [18-19]. Kiti ketamino veikimo mechanizmai yra susiję su monoaminerginiais, muskarininiais, nikotininiais receptoriais, be to, šis vaistas pasižymi ir vietiniu anesteziniu poveikiu [20].

Ketamino dozavimas pooperacinei analgezijai. Ketamino, kaip vaisto pooperaciniam skausmui malšinti, dozavimas dar yra galutinai nenustatytas. Šiuo metu skirtingi tyrèjai naudoja tris pagrindinius dozavimo režimus [21]:

1) vienkartinè injekcija prieš operacijos pradžią (nuo 0,15 iki $0,5 \mathrm{mg} / \mathrm{kg}$ );

2) injekcija prieš operacijos pradžią (nuo 0,15 iki 0,5 $\mathrm{mg} / \mathrm{kg}$ ) pratęsiant infuziją per operaciją ar iki 12-48 val. po operacijos $(0,06-0,18 \mathrm{mg} / \mathrm{kg} / \mathrm{val}$.);
3) infuzija po operacijos $(0,15-0,2 \mathrm{mg} / \mathrm{kg} / \mathrm{val}$.).

Dar nežinoma, kuris dozavimo režimas yra efektyviausias.

Ketamino klinikiniai taikymai gydyti pooperacini skausmą. Kathirvel Subramaniam su bendr. 2004 metais atliko vieną pirmujjų metaanalizių, apibendrindamas ịvairių klinikinių studijų, kurių metu pooperaciniam ūminiam skausmui malšinti greta standartinès opioidinès analgezijos buvo naudotas ketaminas, rezultatus. Autoriai rèmėsi 37 randomizuotomis, dvigubai aklomis studijomis, atliktomis 1966 - 2003 metais. İ metaanalizę itrauktos tik tos studijos, kuriose tiriamieji buvo suskirstyti i 2 grupes: kontrolinès grupès pacientams buvo taikomas standartinis pooperacinio skausmo malšinimo būdas opioidiniais analgetikais, o tiriamosios grupès pacientams kartu su opioidiniais analgetikais kaip adjuvantas buvo skirtas ketaminas. Iš viso studijose dalyvavo 2385 tiriamieji (kontrolinejje grupeje - 1049, tiriamojoje - 1336). Analizuojant kontrolinès ir tiriamosios grupių rezultatus buvo atsižvelgiama ị skausmo intensyvumą, vertinamą vizualinèje analoginèje skaleje (VAS) pirmąsias 24 val. po operacijos, laiko momentą, kada pacientui pirmą kartą reikèjo papildomos opioidinių analgetikų dozès dèl nepageidaujamo šalutinio medikamentų sukelto poveikio. Apibendrinant metaanalizès metu gautus rezultatus, laukiamas ketamino poveikis pasitvirtino 54 proc. studijų. Mažos apimties operacijų, tokių kaip apendektomija, tonzilektomija, laparoskopine chirurgija, kelio sąnario artroskopija, papildomas ketamino skyrimas malšinti pooperacinị skausmą neturèjo reikšmingos įtakos, kadangi tokio pobūdžio skausmą efektyviai malšina standartiniai opioidiniai analgetikai, nesteroidiniai vaistai nuo uždegimo (NVNU), vietinių anestetikų infiltracijos. Būtent todèl tolimesnès klinikinés studijos, siekiant apibréžti ketamino, kaip adjuvanto naudą, turètų būti orientuotos ị didelès apimties operacijas, tokias kaip pilvo ar krūtinės chirurgija. Svarbu paminèti, kad skiriant mažų dozių ketaminą nebuvo stebetas psichomimezinis vaisto poveikis (haliucinacijos, ryški sedacija). Tačiau nepaisant ketamino vartojimo ir pasireiškusio opioidus tausojančio efekto, nepavyko išvengti tokių opioidinių analgetikų šalutinių reiškinių kaip pykinimas, vėmimas, niežulys, kvėpavimo centro slopinimas [6].

2011 metais Canadian Anesthesiologist Society žurnale publikuota dar viena sisteminė Kevin Laskovski ir bendr. apžvalga. Literatūros paieška atlikta naudojantis Medline (1966 - 2010) ir EMBASE (1980 - 2010) duomenų bazėmis. Iš viso rasta 70 klinikinių tyrimų, i kuriuos įtrauktas 4701 pacientas (kontrolinejje grupeje - 2049 pacientai, tiriamojoje -2652). Ivertinus tyrimų atlikimo metodiką, rezultatų pateikimą ir jų kokybę, galutinejje metaanalizejje paliktos 47 randomizuotos, dvigubai aklos studijos, kurių metu naudojamas intraveninis ketaminas, vertinamas pooperacinio skausmo 
intensyvumas ir opioidinių analgetikų poreikis po įvairaus pobūdžio operacijų. Skirtumai rasti lyginant operacijos tipą ir VAS rodiklius, ivertintus tuoj pat po operacijos. Nustatyta, kad daugiausia opioidinių analgetikų poreikis sumažejo po viršutinès pilvo ir krūtinès chirurgijos $(\mathrm{p}<0,001)$. Atliekant mažos apimties galvos ir kaklo, dantų operacijas ar tonzilektomiją, skirtumas, lyginant opioidinių analgetikų suvartojimą po operacijos, rastas nebuvo $(\mathrm{p}=0,631)$. Taip pat buvo vertinamas morfino sunaudojimo skirtumas esant ịvairiam skausmo intensyvumui. Nustatyta, kad skausmo iki 4 balu pagal VAS atveju morfino sunaudojimas tiriamosiose grupese nesiskyrė $(p=0,268)$, priešingai nei esant intensyvesniam skausmui - $\geq 7$ balai pagal VAS ( $<<0,001$ ). Iš viso skausmo intensyvumas, tiriamas $30 \mathrm{~min}$. -4 val. po operacijos sumažèjo 37,5 proc. studijų, o $24-72$ val. po operacijos $-25 \%$ studijų. Nepaisant didesnès suvartotos opioidinių analgetiku dozès, 78\% kontrolinès grupès pacientų jautè intensyvesni skausmą po operacijos, nei tiriamosios grupès pacientai. Lyginant nepageidaujamų poveikių pasireiškimą, tiriamojoje grupeje stebèta daugiau neuropsichiatrinių reiškinių $(p<0,018)$, tačiau mažiau pykinimo ir vėmimo $(p<0,018)$. Vertinant sedaciją, skirtumas tarp grupių nerastas $(\mathrm{p}=0,99)$. Norint tiksliau apibrěžti nepageidaujamų poveikių dažnį, palygintos atskiros studijos, kuomet ketamino vartojimas buvo veiksmingas. Nustatyta, kad šiuo atveju neuropsichiatrinių reiškinių dažnis buvo mažesnis tiriamojoje grupejje $(\mathrm{p}<0,01)[7]$.

Fiorelli A. ir kt. studijoje ištirti 75 pacientai, kuriems $2012-2014 \mathrm{~m}$. buvo atliekama šoninè torakotomija. Pacientai buvo suskirstyti i 2 grupes (kontrolinę ir tiriamają) pagal atsitiktini atrankos metodą. Visiems pacientams buvo taikomas standartizuotas skausmo gydymas pagal protokolą (10 mg morfino po oda $30 \mathrm{~min}$. iki operacijos pabaigos, 30 $\mathrm{mg}$ ketorolako ir $1 \mathrm{~g}$ paracetamolio $\mathrm{i} / \mathrm{v}$ budimo po anestezijos metu, pabudus - morfinas PKA būdu). Tiriamosios grupès pacientams papildomai skausmo malšinimui prieš operacini pjūvị boliusu i $/ \mathrm{v}$ buvo suleista $1 \mathrm{mg} / \mathrm{kg}$ ketamino. Skausmo lygis vertintas $6,12,24,36,48$ val. po operacijos. Nustatyta, kad tiriamosios grupès pacientams reikèjo mažiau morfino, nei kontrolinès grupès (suminè dozè per 48 val. buvo 20,7 $\mathrm{mg}$ ir 24,8 mg, $\mathrm{p}<0,001$ ), o skausmo intensyvumas kontrolinèje grupejje buvo $0,6-0,8$ balo didesnis, nei tiriamojoje $(\mathrm{p}=0,01)$. Tyrimo metu abejose grupèse po operacijos nebuvo stebèta haliucinacijų, košmarų, galvos svaigimo, pykinimo ar vèmimo [9].

Minoshima R. ir kt. autorių atliktame dvigubai aklame, atsitiktinių imčių, placebo kontroliuojamame tyrime tirti 36 pacientai (10 - 19 metų amžiaus), kuriems dèl idiopatinès skoliozès atlikta nugarinè spondilodezè. Visiems pacientams anestezija taikyta propofoliu ir remifentaniliu, o pooperacinio skausmo gydymui skirta morfino paciento kontroliuojamos analgezijos būdu 48 val. po operacijos. Tiriamosios grupès pacientams taip pat buvo skirta ketamino infuzija $2 \mathrm{mcg} / \mathrm{kg} /$ min. per operaciją ir 48 val. po jos. Nustatyta, kad suminé morfino dozè praejus 24 val. ir 48 val. po operacijos buvo mažesnè taikant ketamino infuziją, lyginant su placebo grupe $(0,59 \pm 0,04 \mathrm{mg} / \mathrm{kg}$ ir $0,89 \pm 0,08 \mathrm{mg} / \mathrm{kg}, \mathrm{p}=0,023$, lyginant su $0,75 \pm 0,05 \mathrm{mg} / \mathrm{kg}$ ir $1,16 \pm 0,07 \mathrm{mg} / \mathrm{kg}, \mathrm{p}=0,019)$. Antiemetikų suvartojimas per 48 val. po operacijos taip pat mažesnis buvo ketamino grupeje, lyginant su placebo grupe $(\mathrm{p}=0,03)$. Skausmo intensyvumas (SAS skalè), sedacijos laipsnis, pooperacinis pykinimas ir vėmimas statistiškai reikšmingo skirtumo neturejo [10].

Riham Hasanein ir kt. autorių studijoje, publikuotoje 2011 metais Egyptian Journal of Anaesthesia žurnale, tirtas ketamino poveikis laparoskopinių skrandžio apylankos operacijų metu. Tiriamujų kontingentas $-25-50 \mathrm{~m}$. pacientai, priskirti II - III ASA klasei. Iš viso tirti 60 pacientų, kurie atsitiktiniu atrankos būdu suskirstyti į 2 grupes: kontrolinès grupès pacientams taikyta standartinè anestezija propofoliu ir remifentaniliu, tiriamosios grupés pacientams papildomai taikyta $1 \mathrm{mcg} / \mathrm{kg} / \mathrm{min}$. ketamino infuzija, tęsiama nuo anestezijos indukcijos iki paskutinio laparoskopinio troakaro pašalinimo. Visiems pacientams po operacijos skausmas gydytas morfinu paciento kontroliuojamos analgezijos būdu. Nustatyta, kad tokios didelès apimtiems operacijų metu, vartojant ketaminą, morfino poreikis sumažèjo ne tik pirmujų 2 val. po operacijos metu $(p<0,05)$, bet ir per pirmąsias 24 val. po operacijos $(\mathrm{p}<0,05)$. Vertinant skausmo intensyvumą pagal VAS 1 - ą ir 2 - ą val. po operacijos, tiriamojoje grupejje jis buvo mažesnis, lyginant su placebo grupe $(<0,05)$. Pašalinių reiškinių (pykinimas, vèmimas, haliucinacijos) dažnis tarp grupių nebuvo statistiškai reikšmingas [8].

\section{Išvados}

Ketaminas - vienas iš seniai naudojamų medikamentų, kuriems atsiranda naujos indikacijos. Tradicinis jo panaudojimas - bendrajai anestezijai sukelti. Naudojant mažas, nesukeliančias anestezijos dozes prieš operaciją, jos metu ar iš karto po jos, galima tikètis silpnesnio pooperacinio skausmo ir mažesnio stiprių, opioidinių anestetikų poreikio. Tačiau optimalias analgezines jo dozes dar reikès nustatyti. Mažų ketamino dozių pašaliniai reikškiniai yra silpni ar net visai nepastebimi. Kadangi šis vaistas yra pigus ir saugus, tikètinas platesnis jo panaudojimas, ypač po didelès apimties operacijų, kai bendrojo analgetikų kiekio sumažinimas yra itin svarbus.

\section{Literatūra}

1. Apfelbaum JL, Chen C, Mehta SS, Gan TJ. Postoperative pain experience: Results from a national survey sugest postoperative pain continues to be undermanaged. Anesthesia and Analgesia 
2003; 97:534-540.

https://doi.org/10.1213/01.ANE.0000068822.10113.9E

2. Gan TJ, Habib AS, Miller TE, White W, Apfelbaum JL. Incidence, patient satisfaction and perceptions of postsurgical pain: Results from a US national survey. Current Medical Research and Opinion 2014; 30:149-160.

https://doi.org/10.1185/03007995.2013.860019

3. Kehlet H, Jensen T, WoolfC. Persistent postsurgical pain: Risk factors and prevention. Lancet 2006; 367:1618-1625. https://doi.org/10.1016/S0140-6736(06)68700-X

4. Chou R, Gordon Debra B, de Leon - Casasola OA, Rosenberg JM, Bickler S. at al. Management of postoperative pain: a clinical practice guideline from American pain society, the American society of regional anesthesia and pain medicine, and the American society of anesthesiologists' committee on regional anesthesia, Executive committee, and Administrative council. Journal of Pain 2016; 17(2):131-157.

https://doi.org/10.1016/j.jpain.2015.12.008

5. Gritsenko K, Khelemsky Y, Kaye DA. et al. Multimodal therapy in perioperative analgesia. Best Practice\&Research Clinical Anaesthesiology 2014; 28:59-79.

https://doi.org/10.1016/j.bpa.2014.03.001

6. Subramaniam K, Subramaniam B, Steinbrook RA. Ketamine as adjuvant analgesic to opioids: a quantitative and qualitative systematic review. Anesthesia and Analgesia 2004; 99:482-95. https://doi.org/10.1213/01.ANE.0000118109.12855.07

7. Laskowski K, Stirling A, McKay WP, Lim HJ. A systematic review of intravenous ketamine for postoperative analgesia. Can J Anaesth 2011; 58:911-23. https://doi.org/10.1007/s12630-011-9560-0

8. Hasanein R, El-Sayed W, Nabil N, Elsayed G. The effect of combined remifentanil and low dose ketamine infusion in patients undergoing laparoscopic gastric bypass. Egyptian Journal of Anaesthesia 2011; 27:255-260.

https://doi.org/10.1016/j.egja.2011.07.009

9. Fiorelli A, Mazzella A, Passavanti B, Sansone P, Chiodini P, Iannoti $\mathrm{M}$. et al. Is pre-emptive administration of ketamine a significant adjunction to intravenous morphine analgesia for controlling postoperative pain? A randomized, double-blind, placebo-controlled clinical trial. Interact CardioVasc Thorac 2015; 21:284-91.

https://doi.org/10.1093/icvts/ivv154

10. Minoshima R, Kosugi S, Nishimura D, Ihara N, Seki H, Yamada $T$. et al. Intra - and postoperative low-dose ketamine for adolescent idiopatic scoliosis surgery: a randomized controlled trial. Acta Anaesthesiologica Scandinavica Foundation 2015; 59:1260-1268

https://doi.org/10.1111/aas.12571

11. Domino EF. Taming the ketamine tiger.1965.Aneshesiology 2010; 113:678-684.

12. Domino EF, Chodoff P, Corssen G. Pharmacologic effects of CI-581, a new dissociative anesthetic, in man. Clin Pharmacol Ther $1965 ; 6: 279-91$.

https://doi.org/10.1002/cpt196563279
13. Corssen, G \& Domino, EF. Dissociative anesthesia: further pharmacologic studies and first clinical experience with the phencyclidine derivate CI-581. Anesthesia and analgesia current researches 1966 Jan - Feb; 45(1):29-40.

14. Corssen G, Miysaka M, Domino EF. Changing concepts in pain control during surgery: dissociative anesthesia with CI - 581 . Anesthesia and Analgesia current researches 1968 Nov - Dec; 45(6):746-758.

15. Anis NA, Berry SC, Burton NR, Lodge D. The dissociative anaesthetics, ketamine and phencyclidine, selectively reduce excitation of central mammalian neurons by N-methyl-aspartate. Br. J. Pharmacol 1983; 79:565 - 75. https://doi.org/10.1111/j.1476-5381.1983.tb11031.x

16. Hirota K, Lambert D.G. Ketamine: new uses for an old drug? British Journal of Anaesthesia 2011; 107(2):123-6. https://doi.org/10.1093/bja/aer221

17. Chapman V, Dickenson AH. The combination of NMDA antagonism and morpfhine produces profound antinociception in the rat dorsal horn. Brain Research 1992; 573:321-323 https://doi.org/10.1016/0006-8993(92)90780-D

18. Bell R, Eccleston C, Kalso E. Ketamine as an adjuvant to opioids for cancer pain. Cochrane Database of Systematic Reviews 2012; 11:CD003351. https://doi.org/10.1002/14651858.cd003351.pub2

19. Visser E, Schug SA. The role of ketamine in pain management. Biomedicine and Pharmacotherapy 2006; 60:314-8. https://doi.org/10.1016/j.biopha.2006.06.021

20. Persson J. Ketamine in Pain Management. CNS Neuroscience\&Therapeutics 2013; 19:396-402.

https://doi.org/10.1111/cns.12111

21. Jouguelet-Lacoste J, La Colla L, Schilling D, Chelly JE. The use of intravenous infusion or single dose of low-dose ketamine for postoperative analgesia: a review of the current literature. Pain Med 2015;16(2):383-403.

https://doi.org/10.1111/pme.12619

\section{KETAMINE FOR POSTOPERATIVE PAIN MANAGEMENT \\ G. Kasputyte், A. Karbonskienè}

Key words: ketamine, acute pain, postoperative pain, postoperative pain management.

Summary

Effective postoperative pain management enhances early postoperative rehabilitation and may improve outcomes of surgical treatment. New analgetic medications and combinations of these are sought for optimal analgesia with lowest possible incidence of side effects. Ketamine is an old general anaesthetic. Low doses of it might be used as a adjunct in postoperative analgesia. An overview of data which show that low-dose ketamine is safe and posess opioid-sparing effect in postoperative pain management is presented in this article.

Correspondence to: Aurika.Karbonskiene@kaunoklinikos.lt

Gauta 2017-05-29 